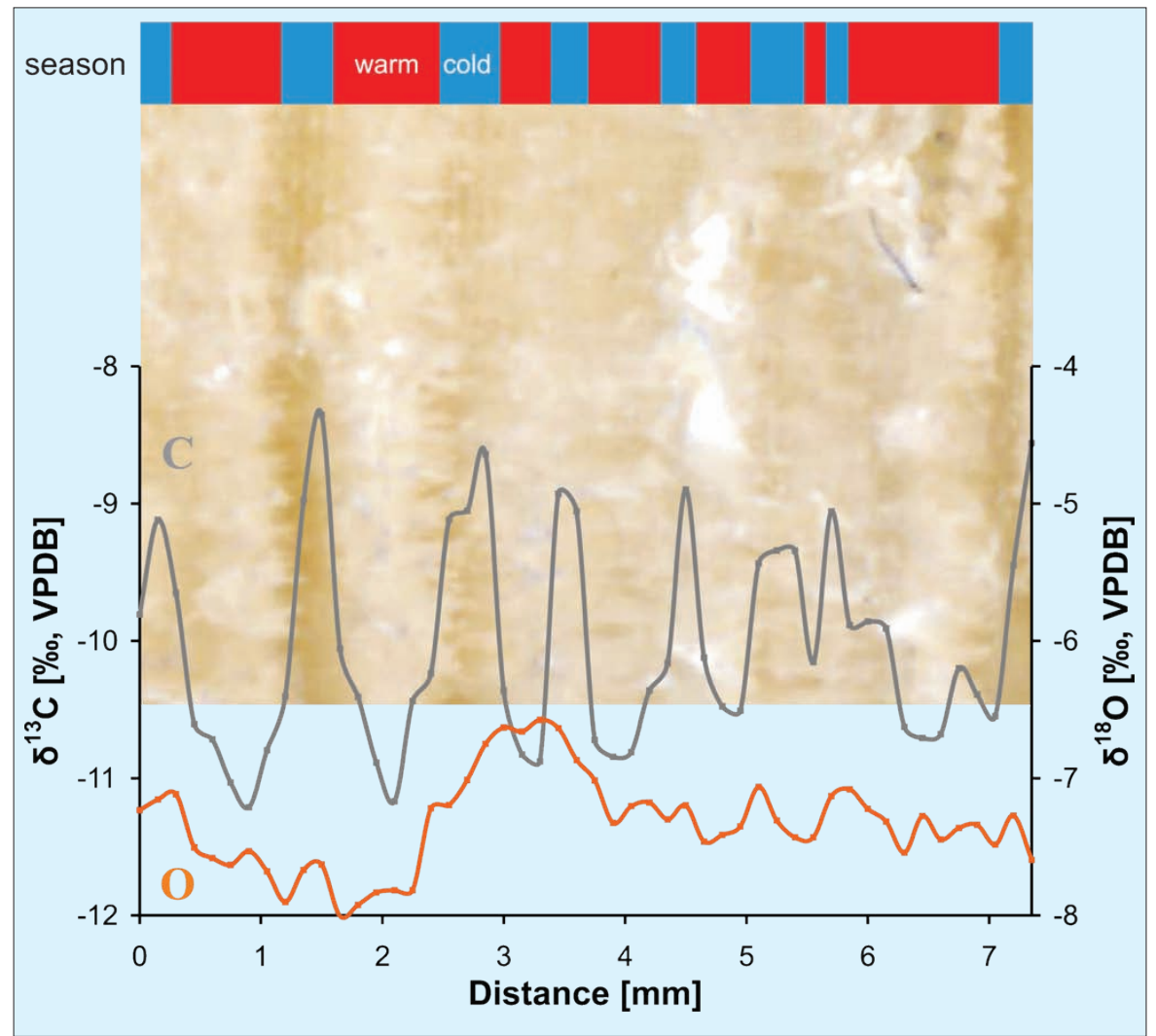

Figure 2: Example of the stable isotopic composition of a laminated Last Interglacial stalagmite from Katerloch Cave: White, porous laminae typically coincide with low calcite $\delta^{13} \mathrm{C}$ values and cave monitoring indicates that these laminae form during the warm season when cave air and drip water C isotope values are low (sluggish air exchange, relatively high $\mathrm{CCO}_{2}$ level). Translucent, dense laminae show high $\mathrm{C}$ isotope values and form during the cold season (enhanced air exchange, low pCO, level and kinetically controlled C isotope fractionation). The $O$ isotopes, in contrast, are unaffected by these seasonal oscillations and record multi-annual changes.

aquifer, i.e., the mean residence time of the water in the vadose zone (the zone between the land surface and the water table) is well above one year. Likewise, $\mathrm{O}$ isotope data from the stalagmites do not follow the high-frequency (seasonal) variability of the $C$ isotope data but show rather gradual, multi-annual changes (Fig. 2). In addition to the seasonal air-exchange dynamics (driven by temperature contrasts), the lamina thickness data are also a record of the amount of meteoric precipitation (or, more precisely speaking, of the net infiltration) in the catchment area. This is consistent with other studies including cold season, the lamination is primarily a proxy of the intensity of winter air circulation in the cave and, hence, of winter air temperature. For example, long and cold winters give rise to relatively thick, translucent and dense laminae showing high $C$ isotope values. In addition, the lamina thickness also reflects the amount of precipitation that recharges the karst aquifer. Wet years promote thick laminae due to increased drip rates (enhanced ionic supply). The relative thickness, however, of summer and winter laminae will eventually also depend on the specific flow conditions at a particular drip site. This study therefore highlights the value of cave monitoring in order to understand the speleothem growth dynamics at a specific cave site, which is an indispensible requirement for exploiting lamination patterns as a quantitative seasonal climate proxy. Given the scarcity of reliable winter proxy data in most currently available terrestrial paleoclimate archives, dynamically ventilated caves such as Katerloch offer a potentially unique opportunity to fill this gap.

\section{References}

Baker, A., Genty, D., Dreybrodt, W., Barnes, W.L., Mockler, N.J., and Grapes, J., 1998: Testing theoretically predicted stalagmite growth rate with recent annually laminated samples: Implications for past stalagmite deposition, Geochimica et Cosmochimica Acta, 62: 393-404.

Frisia, S., Borsato, A., Fairchild, I.J., and McDermott, F., 2000: Calcite fabrics, growth mechanisms and environments of formation in speleothems from the Italian Alps and southwestern Ireland, Journal of Sedimentary Research, 70: 1183-1196.

Kaufmann, G., 2003: Stalagmite growth and palaeo-climate: the numerical perspective, Earth and Planetary Science Letters, 214 251-266.

Mattey, D. Lowry, D., Duffet, J., Fisher, R., Hodge, E. and Frisia, S., 2008 A 53 year seasonally resolved oxygen and carbon isotope record from a modern Gibraltar speleothem: reconstructed drip water and relationship to local precipitation, Earth and Planetary Science Letters, 269: 80-95.

Meyer, M., Faber, R. and Spötl, C., 2006: The WinGeol Lamination Tool: new software for rapid, semi-automated analysis of laminated climate archives, The Holocene, 16: 753-761.

\title{
Precipitation records of the last century reconstructed from annual growth-rate parameters of two Ethiopian stalagmites
}

\author{
Asfawossen Asrat ${ }^{1}$ and Andy BakeR ${ }^{2}$ \\ 'Department of Earth Sciences, Addis Ababa University, Ethiopia; asrata@geol.aau.edu.et \\ ${ }^{2}$ School of Geography, Earth and Environmental Sciences, University of Birmingham, UK; a.baker.2@bham.ac.uk
}

The Ethiopian highlands, located in the central section of the horn of Africa, are one of Africa's rain sensitive regions where monsoon rainfall variability plays a key role in triggering frequent droughts. The region is subject to the seasonal migration of the Inter-Tropical Convergence Zone (ITCZ) and is very sensitive to monsoon variability (Seleshi and Zanke, 2004). The main rainy season (July-September) oc- curs when the northward movement of the ITCZ dominates the airflow, while the spring rainy season (March-May) coincides with the southward migration of the ITCZ. 
Ethiopia, being a largely agricultural country, is severely affected by even slight anomalies or irregularities of monsoon rainfall. However, inadequate understanding of historical patterns and their wider associations and causes, hamper our understanding of the climate system and the reliability of climate projections for the region. Moreover, instrumental weather records in the region are short (rarely longer than 30 years) and of poor quality, making calibration and, subsequently, forecasting of drought and flood events difficult. Long, high-resolution climate records are therefore required to investigate the nature of rainfall variability, the frequency of failure of rain periods, and the presence of decadal to centennial periodicity in climate that cannot be detected through short instrumental series.

To address this urgent problem, we have made use of recent advances in the understanding of the climatic meaning of parameters derived from well-dated speleothems (Fairchild et al., 2006). Since 2004, we have been conducting multi-proxy analysis of speleothems from the Mechara karst system located in the southeastern Ethiopian highlands (Fig. 1a), and have de-

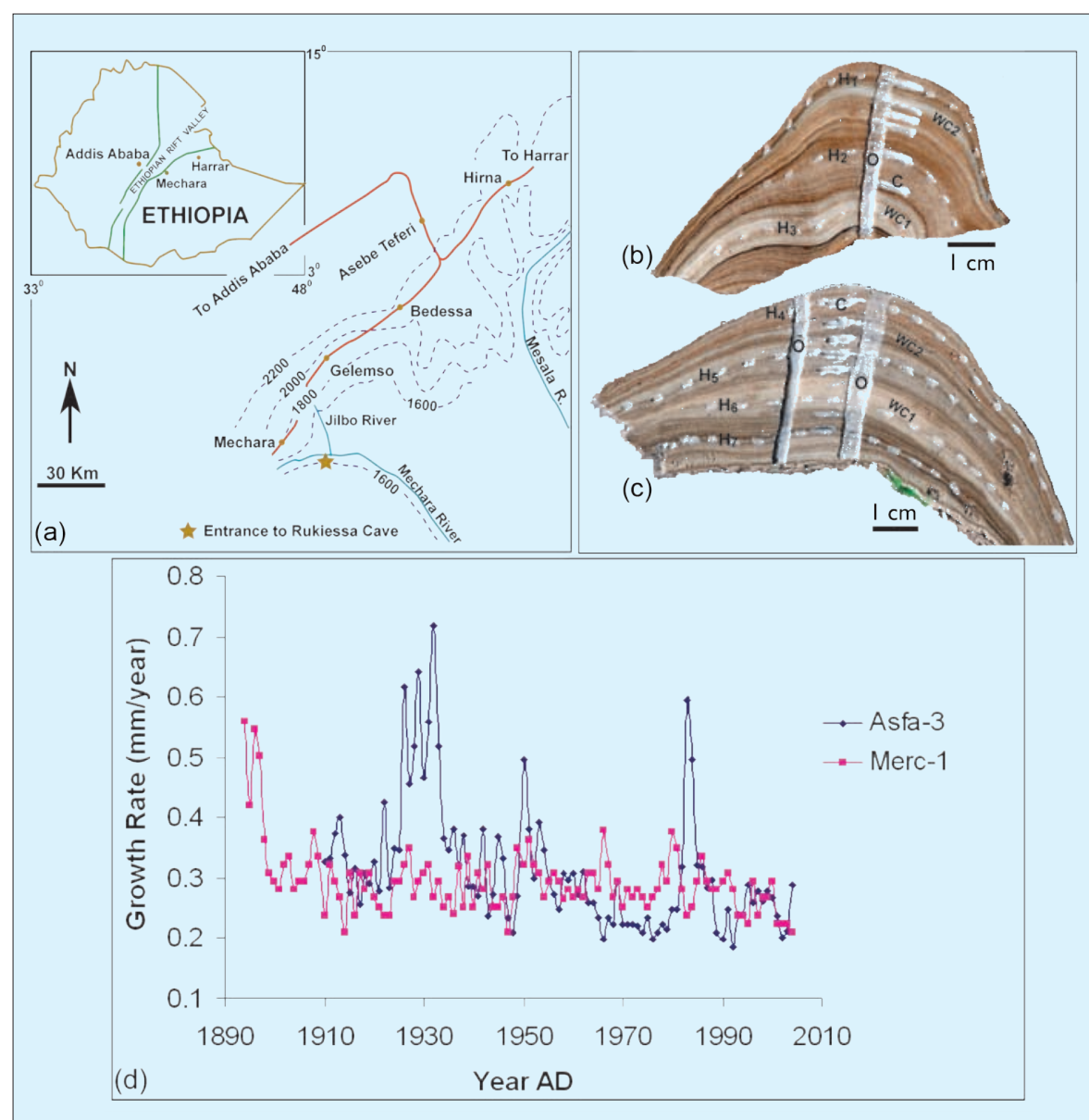

Figure 1: a) Location of sample site: Meteorological stations are located at Mechara, Gelemso, and Bedessa; $\boldsymbol{b}$ ) and c) Stalagmites Asfa-3 and Merc-1, respectively. Also shown are isotope profiles (vertical suites of samples labeled $\mathrm{O}$; duplicate analyses on Merc-1); and horizontal suites of samples labeled $\mathrm{H}_{1-7}$; and samples for ${ }^{14} \mathrm{C}$ analyses labelled C; see Baker et al., 2007). WC and WC2 refer to white (colorless) calcite layers that correlate between the two stalagmites; d) Time series of growth rate for Asfa-3 (blue diamonds) and Merc-1 (pink squares). Figure modified from Baker et al., 2007. rainfall series. Here, we present only the morphological and growth rate data and their relation to precipitation data.

Asfa-3 and Merc-1 (Fig. 1b and c, respectively) were being actively dripped upon when collected from depths of about $30 \mathrm{~m}$ and $25 \mathrm{~m}$, respectively in Rukiessa cave (average temperature: $19^{\circ} \mathrm{C}$; relative humidity: $97 \pm 2 \%$ ). They are both between 50 and $100 \mathrm{~mm}$ high, exhibiting continuous visible laminae. Merc- 1 has a broader width-to-height ratio than Asfa-3, while observed drip rates onto Asfa-3 were much slower than onto Merc-1, suggesting that Asfa-3 was predominantly fed by stored groundwater, whereas Merc-1 had a greater proportion of event water.

Lamina counting conducted on these stalagmites (following the protocol of Tan et al., 2006) revealed a total of 94 laminae in Asfa-3 and 111 laminae in Merc-1. Lamina widths typically varied between 0.2 and $0.4 \mathrm{~mm}$ (Fig. 1d), with some thicker laminae in periods of colorless calcite deposition in Asfa-3 (WC1 and WC2 in Figure 1). Laminae deposition was continuous, and the lamina width matches that predicted for annual accumulation based on the temperature of the cave, atmospheric $\mathrm{PCO}_{2}$ and calcium and magnesium concentrations of the drip waters. Assuming annual deposition, Asfa-3 and Merc-1 were deposited from 1910 AD and 1894 $A D$, respectively, until sampled in 2004.

\section{Growth rate as a rainfall proxy}

The two stalagmites have similar mean growth rates but differing growth rate variability. Asfa-3 has long periods of very stable growth rates, interspersed with jumps to short periods of fast growth. Mer-1 has a more constant growth rate but with greater interannual variability. We correlated the growth rate series (monthly, seasonal and annual means) of both stalagmites against the instrumental rainfall series, as well as appropriate linear'climate transfer functions' that smoothed previous years' monthly, seasonal and annual rainfall in a manner that potentially reflects the mixing of waters of different ages within the limestone aquifer. Correlations with the amount of rainfall in the year of calcite deposition were weak and statistically insignificant (Fig. 2a and b). Seasonal and smoothed correlations were stronger, especially for Asfa-3, for which decadal averaged growth rate correlated with JuneAugust rainfall $(r=0.50)$. Applying the climate transfer function demonstrated that, for this sample, a simple decadal average had a correlation that was statistically as strong as a more complex climate transfer function. The reconstructed summer 
rainfall, based on a transfer function of $10 \%$ 'event' water (May-July rainfall of that year) and $90 \%$ 'storage' water (an average of May-July rainfall of the previous nine years), is presented in Figure 2c.

In contrast, only weak correlations between growth rate and precipitation were observed for Merc-1. As this sample was fed by a more variable drip rate, as inferred from its morphology and cave observations, this weak correlation suggests that greater drip water flow variability confounds any strong correlations between lamina width and surface climate. Applying the same transfer functions as for Asfa-3, it can be seen that the function leading to the strongest correlations has a greater proportion of relatively short residence-time water (20\% event water, $80 \%$ stored water of $<5$ years). The strongest correlation was with July rainfall, again reflecting increased water availability, as well as probable increased soil $\mathrm{CO}_{2}$ but the correlation coefficient was only 0.30 and therefore growth rate in this stalagmite is of little use for rainfall reconstruction.

\section{Conclusions}

Our recent studies (Baker et al., 2007; Asrat et al., 2007) show that multiple parameters (e.g., oxygen isotopes, growth rate) from individual stalagmites have different climate sensitivities and would yield contrasting proxy-climate forcing functions. Multi-parameter, multi-proxy approaches are essential when using stalagmites to reconstruct climate, due to the individual nature of the link between surface climate and cave stalagmite, resulting from the heterogeneity and complexity of karst groundwater flow (Fairchild et al., 2006). From their morphology, it would be ex-
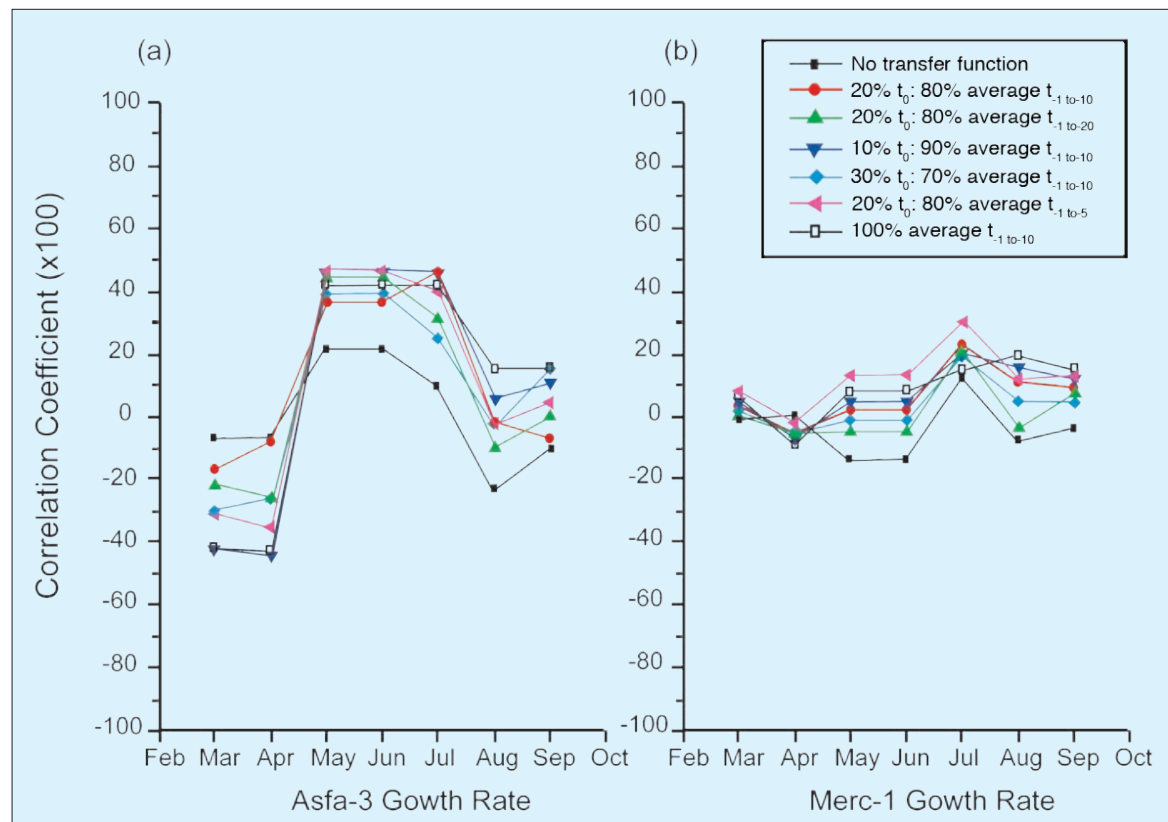

(c)

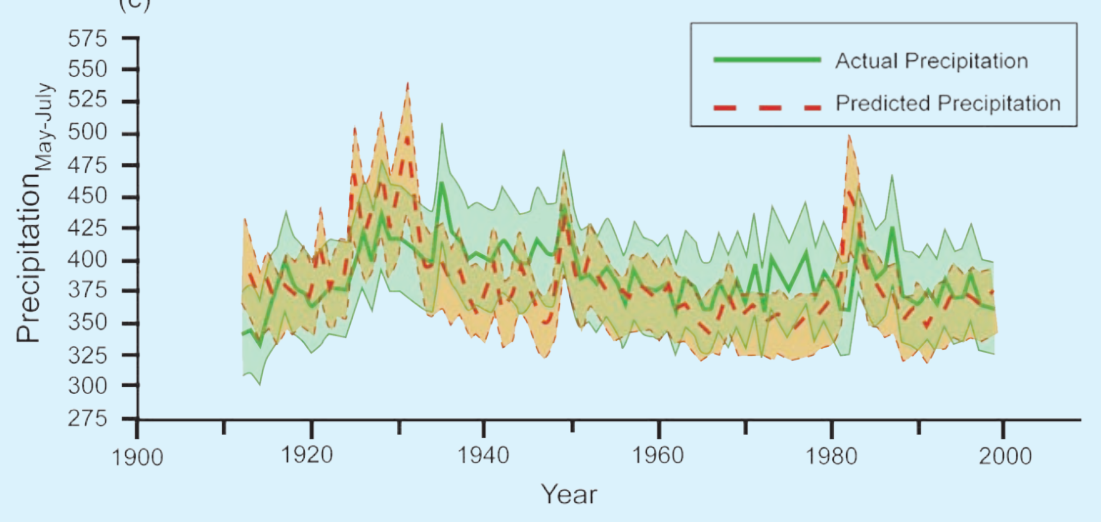

Figure 2: Correlation coefficients between monthly rainfall and stalagmite parameters: $\boldsymbol{a}$ ) Asfa-3 growth rate and b) Merc-1 growth rate, with various transfer functions of the preceding years' rainfall:e.g., the simplest'no transfer function' option, which is a correlation with that years' rainfall in the given month against growth rate (black filled square); correlation of the average of last 10 years rainfall for a given month against growth rate (black open square): a transfer function that is weighted 10\% on the given month's rainfall that year ('event' water) and $90 \%$ on the rainfall of the preceding nine years ('storage' water) for the given month, correlated against growth rate (blue inverted triangle). Correlation coefficients are shown $x 100$ for clarity; c) May-July rainfall reconstructed from Asfa-3 growth rate, applying a transfer function of 10\% 'event' water (May-July rainfall of that year) and 90\% 'storage' water (an average of May-July rainfall of the previous nine years); errors on reconstructed precipitation are based on regression errors, errors on instrumental precipitation reflect differences between local and Addis Ababa series. Figure modified from Baker et al. (2007). pected that Merc-1 responded more to high frequency ('event') precipitation, while Asfa-3 to low frequency ('storage') climate. Despite this, it is Asfa-3 that has a greater range of lamina width due to short periods of fast growth associated with changes in calcite texture. Different parameters (e.g., $\mathrm{O}$ and $\mathrm{C}$ isotopes, growth rate) also respond to different seasons, and in some cases the same parameter responds to different months or seasons via different forcing mechanisms (e.g., rainfall seasonality or amount, or non-equilibrium factors). For our stalagmites, growth rate is among the various parameters that show the highest correlations with monthly or seasonal mean rainfall. Therefore, we propose that growth rate, as part of multiparameter, multi-proxy analyses of long time series of speleothems, offers a most promising approach to characterizing the variability of rainfall in this region, where the population largely depends on rainfed agriculture for survival.

\section{References}

Asrat, A., Baker, A., Umer, M., Leng, M.J., van Calsteren, P. and Smith, C., 2007: A high-resolution multi-proxy stalagmite record from Mechara, Southeastern Ethiopia: palaeohydrological implications for speleothem palaeoclimate reconstruction, Journal of Quaternary Science, 22: 53-63.

Baker, A., Asrat, A., Fairchild, I.J., Leng, M.J., Wynn, P.M., Bryant, C., Genty, D. and Umer, M., 2007: Analysis of the climate signal contained within $\delta^{18} 0$ and growth rate parameters in two Ethiopian stalagmites, Geochimica et Cosmochimica Acta, 71: 2975-2988.

Fairchild, I.J., Smith, C.L., Baker, A., Fuller, L., Spotl, C., Mattey, D., McDermott, F. and E.I.M.F., 2006: Modification and Preservation of environmental signals in speleothems, Earth Science Reviews, 75: $105-153$.

Seleshi, Y. and Zanke, U., 2004: Recent changes in rainfall and rainy days in Ethiopia, International Journal of Climatology, 24: 973-983.

Tan, M., Baker, A., Genty, D., Smith, C., Esper, J. and Cai, B., 2006: Applications of stalagmite laminae to paleoclimate reconstructions: comparison with dendrochronology/climatology, Quaternary Science Reviews, 25: 2103-2117. 